courses in operation, with approximately three thousand students taking part. The rapid recent growth of courses is shown by the fact that five hundred students completed sandwich courses last summer, whereas the intake last autumn was more than a thousand. 'There is, however, a long way to go, for the objective of the Whito Paper is to raise the three thousand to twenty thousand, with five thousand enrolling each year.

This renewal of interest on the part of industry in Britain in the sandwich course is a remarkable sign of the times, for such courses have been operating in a few colleges since the beginning of the century. Until the Second World War, industry was well served by the combination of degree men and men who managed to achieve professional status by evening study based on a Higher National Certificate. Industry has always valued the type of man who achieved qualifications the 'hard way'; but this is a wasteful method of producing a considerable proportion of technologists when the need is to raise to the technological level every person capable of achieving this end.

A great deal of work must be done on the integration of works training and college study-periods. Co-operation between industry and colloges is important in overy branch of technical education, but for sandwich courses it is basic and it has to be of a particularly intimate kind. Both colleges and firms must be convinced they have worked out the type of scheme best suited to the circumstances. These considerations would cover the length of the course, the length of the sandwich period, selection, reporting procedures and the possibility of the doubling-up principle whereby students are 'paired', with alternately one at colloge while his partner is at the works.

Wastage during courses is a familiar feature of technical education. A high rate of wastage must be avoided in sandwich courses not only because failure to make the grade means inefficient use of students and staff, but also because it is bad for the student, educationally and psychologically. 'This problem could be solved by a rigorous selection policy, following the pattern of the university rather than the general technical college.

The grammar and secondary technical schools will provide the bulk of the sandwich-course entrants; but it should be remembered that one-quarter of successful candidates in Higher National Certificate examinations have como from secondary modern schools. The National Certificate route should be kept in mind, for it keeps open a path for the secondary modorn school pupil. By providing a diversity of routes to high qualifications, sandwich courses play a vital part in the new pattern of educational opportunity.

A considerable part of the discussion was devoted to questions of finance, and it was clear that a dofinite policy is required in the form of a government lead. There were differences of opinion on the part that should be played by small firms. On one hand, it is very difficult for small firms to make the works periods progressive and worth while: on the other hand, large firms claim they are at saturation point in training for their own requirements, and they are unable to accept college-based students for practical training. The suggestion that small firms cannot afford the cost was contradicted by a speaker who pointed out that if a small firm accepted a number of apprentices bearing the same ratio to the number of employees as the large firm, the proportional cost would be approximately the same.

Tho problem presented by the contribution of small firms towards training was taken up by Sir Norman Kipping, director-general of the Federation of British Industries, in his summing up of the Conference. Sir Norman quoted figures which indicated the large proportion of the ten million people employed in the British Isles working for small firms. No less than four million people work either for themselves or in firms with less than one hundred employees. He did not agree with the complete rejection of the economic justification for liberal education and there is, in his mind, a fleeting doubt whether the injection of liberal subjects is right for all students. If the prime justification for liberalizing technical courses is to provide leaders of other men, he said, attention should be directed to the fact that relatively few technical men do lead at the present time in Great Britain.

\section{MOLECULAR MECHANISM OF RATE PROCESSES IN SOLIDS}

$T$ HE Faraday Society, at the invitation of, and in conjunction with, the Koninklijke Nederlandse Chemische Vereniging, held its first discussion meoting of 1957 at the Koninklijke Institut voor de Tropon, Amsterdam, during April 15-18. The meeting created a precedent in that it was the first to be held on the Continent, although the Society had collaborated with the Société de Chimie Physique in a discussion on surface chemistry at Bordeaux in October 1947, and had held a general discussion, in September 1952, at Toronto. The present meeting again emphasized how the Society ondeavours to encourage international interest in its work, and indoed its success is exemplified by the appearance of papors from America, Australia, Cermany, Holland, Italy, Sweden and Switzerland.

The general subject had been somewhat arbitrarily divided into three main sections : relaxation processes ; and steady-state processes involving, and not involving, lattice re-arrangement. Practically all the time of the meeting was devoted to lively and critical discussion of the papers which had been pre-printed and circulated well ahead of the conference. Members were welcomed by Mr. R. P. Bell, president of the Faraday Society, who, with Prof. Gerding, president of the Royal Dutch Chemical Society, shared the duties of chairman.

Prof. C. J. F. Eottcher (Leyden) introduced the first section with a concise review on the general principles of relaxation processes, and this was followed with a contribution by Dr. H. C. Brinkman and F. Schwarz (T.N.O., Delft) in which they presented a theory of the non-linear relaxation of solids in terms of a diffusion process of molecular groups over potential barriers and discussed the morits and drawbacks of this now approach. The mechanisms by which dislocations cause energy losses, namely, by hysteresis, resonance and relaxation, were outlined by Dr. A. Seeger, H. Douth and F. Pfaff (Max-Planck Institute, Stuttgart), and results were reported of calculations of the rate and activation energy of the process in which the Bordoni relaxation poak was attributed to dislocations overcoming the Peierls stress by thermally activated kink formation. Dr. R. H. Cole and S. Havrilak (Brown 
University) dealt with further work on dielectric relaxation in solid hydrogen halides, and stressed the importance of dipole interactions for the structure and rates of molecular orientation in the low-temperature phase. A similar study by Dr. J. S. Dryden and R. J. Meakin (National Standards Laboratory, Chippendale, New South Wales), on some alkali halides containing divalent cation impurity, showed that the activation energy from the lower frequency absorption is associated with the orientation of the dipole of the divalent cation, and with ion-vacancy aggregate. Their results were in agreement with those obtained from d.c. conductance, if correctly interpreted, and with the heights of the energy barrier theoretically obtained from the elastic constants of the crystal. The paper by Dr. H. Gränicher, C. Jaccard, P. Scherrer and S. Steinemann (Zurich) on the theory of the dynamic behaviour of ice, in which the polarization changes were ascribed to orientational defects and ionized states, provoked some stimulating discussion, particularly on the Pauling theoretical value for the zero-point entropy. The first section concluded with a contribution by Dr. J. Volger (Eindhoven) on the dielectric loss in insulators containing impurity and colour centres, in which relaxation times were associated with very small activation energies; these latter cannot be attributed to migration losses and merit further study.

A concise review by Prof. J. S. Koehler and F. Seitz (Illinois) on point, line and planar imperfections introduced the second section. Prof. F. G. Fumi and M. P. Tosti (Palermo) then reported on some calculations of the energies to form and move vacancies in sodium and potassium chlorides, and Dr. J. Crank (Courtaulds, Ltd., Maidenhead) discussed the definition, measurement and interpretation of diffusion coefficients in solids. A comparatively new aspect of diffusion theory, the correlation between consecutive jumps of the mobile carrier, was developed by K. Compaan and Dr. Y. Haven (Philips, Eindhoven), who showed that this effect alters the self-diffusion coefficient in certain circumstances, but does not affect the ionic conductance; there thus seems some hope of disentangling diffusion mechanism in ionic crystals in greater detail. A somewhat neglected approach-the theory and measurement of thermoelectric power of ionic crystals - was the subject of a paper by R. E. Howard (Oxford) and Dr. A. B. Lidiard (Harwell), and F. P. Clarke (Harwell) reviewed the production of defects by irradiation and the kinetics of their annealing. Prof. W. Jost and Dr. H. Oel (Göttingen) reported briefly on their work on the sintering processes in silver iodide, and Prof. F. C. Frank (Bristol) gave a clear account of the interaction of point defects with dislocations. He briefly surveyed the very interesting methods of decorating dislocations in alkali halides that are being developed by Dr. J. W. Mitchell and his colleagues at Bristol. A short, but stimulating, discussion by Prof. A. R. Ubbelohde (Imperial College, London) on abnormal $A$ and $E$ factors in solid processes encouraged a lively exchange of views -not all, it must be admitted, related to the main aspect of the paper.

The third section comprised a group of contributions on individual topies which were not too closely related, but Prof. J. H. de Boer (Staatsmijnen, Limburg), in his introductory address, did much to give coherence and greater breadth to this field of study. Two papers were concerned with allotropic transformation-that on tin by Prof. W. Gr. Burgers and Dr. L. J. Groen (Delft), in which they stressed the mechanistic and kinetic aspects, and the other on sulphur by C. Briske and Dr. N. H. Hartshorne (Leeds), who were largely concerned with orientational effects. The latter authors created great interest by their colour cine-film that illustrated the various facets of the transformation. The two remaining contributions differed widely in subject-matter. Dr. F. C. Tompkins and Dr. D. A. Young (Imperial College, London) discussed the information provided by conductance and absorption spectra on the annealing and thermal decomposition of azide crystals, and Mrs. M. M. de Maine, Dr. A. G. Maddock and K. Taũgbŏl (Cambridge) concluded the meeting with an account of their investigation on the kineties of a radical recombination process following radiative thermal neutron capture.

In addition to the scientific activities, there were many social events, which had been arranged by the Nederlandse Chemische Vereniging. These included an official reception at the Rijksmuseum by the Burgomaster of Amsterdam, dinner at the Cariton Restaurant, a boat-trip through the canals and harbour of Amsterdam at the invitation of the Municipality, and a day excursion to the nature reservation, Hoge Veluwe, and its picture gallery. Both Societies should be congratulated on the high level of the scientific discussion and the excellent organization of the whole meeting. It is to be hoped that this will be the first of many meetings of the Faraday Society on the Continent.

F. C. TOMPKINS

\section{BRITISH RAYON RESEARCH ASSOCIATION OPEN DAYS}

$T$ HE British Rayon Research Association held the second of its annual open days on May 9 and 10 . More than 4.50 visitors attended on the first day, and between 300 and 350 on the second. All the work of the Association was shown, with the exception, because of the present patent position, of some of the developments of fluid bed technique applied to textile processes involving heat transfer. All the staff is now at Heald Green, Manchester, the premises at Barton Dock Road having been vacated. An additional technological building at Heald Green is being planned, and it is hoped that construction will start soon.

Work on the hot alkaline degradation of cellulose in the absence of oxygen has been continued. A detailed chemical analysis of the products of this degradation has been carried out. 'The main products are acidic, the amount of neutral products being very small. Eight of these acidic products have been identified, the major constituent being $\mathrm{D}$-glucoisosaccharinic acid. These products are formed by attack at the reducing end of the cellulose chains, but the mechanism of formation is certain only for isosaccharinic acid. Consideration is now being given to labelling specific carbon atom positions with carbon-14, in the first place in model compounds, and then in the cellulose molecule, in order to throw further light on the mechanism of degradation. Simultaneously with the degradation reaction, there is a 'stopping reaction' which renders the cellulose stable to alkali. It has been shown that this 'stopping 